\title{
Metabolomics-based Discovery of Serum Biomarkers to Predict the Side-effects of Neoadjuvant Chemoradiotherapy for Esophageal Squamous Cell Carcinoma
}

\author{
SHIN NISHIUMI ${ }^{1 *}$, SEIJI FUJIGAKI ${ }^{1 *}$, TAKASHI KOBAYASHI ${ }^{1}$, TAKASHI KOJIMA ${ }^{2}$, \\ YOSHINORI ITO ${ }^{3,4}$, HIROYUKI DAIKO ${ }^{5}$, KEN KATO $^{6}$, HIROKAZU SHOJI $^{6}$, \\ YUZO KODAMA $^{1}$, KAZUFUMI HONDA ${ }^{7,8}$ and MASARU YOSHIDA ${ }^{1,8,9}$ \\ ${ }^{1}$ Division of Gastroenterology, Department of Internal Medicine, \\ Kobe University Graduate School of Medicine, Hyogo, Japan; \\ ${ }^{2}$ Department of Gastrointestinal Oncology, National Cancer Center Hospital East, Chiba, Japan; \\ ${ }^{3}$ Department of Radiation Oncology, National Cancer Center Hospital, Tokyo, Japan; \\ ${ }^{4}$ Department of Radiation Oncology, Showa University School of Medicine, Tokyo, Japan; \\ ${ }^{5}$ Department of Esophageal Surgery, National Cancer Center Hospital, Tokyo, Japan; \\ ${ }^{6}$ Department of Gastrointestinal Medical Oncology, National Cancer Center Hospital, Tokyo, Japan; \\ ${ }^{7}$ Department of Biomarkers for Early Detection of Cancer, \\ National Cancer Center Research Institute, Tokyo, Japan; \\ ${ }^{8}$ AMED-CREST, Japan Agency for Medical Research and Development, Tokyo, Japan; \\ ${ }^{9}$ Division of Metabolomics Research, Department of Internal Related, \\ Kobe University Graduate School of Medicine, Kobe, Japan
}

\begin{abstract}
Background/Aim: Neoadjuvant chemoradiotherapy has side-effects that adversely affect patients' quality of life. The aim of this study was to identify serum metabolite biomarkers that might be used to predict the side-effects of neoadjuvant chemoradiotherapy for esophageal squamous cell carcinoma (ESCC). Patients and Methods: Metabolomic analysis of serum samples from 26 patients with ESCC that were collected before neoadjuvant chemoradiotherapy was performed. The metabolites associated with hematological toxicity or nephrotoxicity were evaluated. Results: Serum levels of glutaric acid, glucuronic acid, and cystine were significantly higher in hematological toxicity, and phosphatidylcholines and phosphatidylethanolamines exhibited a tendency to be higher in those with hematological toxicity. The serum level of pyruvic
\end{abstract}

*These Authors contributed equally to this study.

Correspondence to: Shin Nishiumi and Masaru Yoshida, Division of Gastroenterology, Department of Internal Medicine, Kobe University Graduate School of Medicine, 7-5-1, Kusunoki-cho, Chuo-ku, Kobe, Hyogo 650-0017, Japan. Tel: +81 783826305, Fax: +81 783826309, e-mail: nishiums@med.kobe-u.ac.jp

Key Words: Esophageal squamous cell carcinoma, metabolomics, biomarker, side-effect, neoadjuvant chemoradiotherapy, 5-flurouracil, cisplatin. acid was significantly lower in nephrotoxicity, and lysophosphatidylcholines and lysophosphatidylethanolamines tended to be lower in those with nephrotoxicity. Conclusion: Our study found that serum levels of some metabolites differed significantly between patients with and without hematological or renal side-effects. These metabolites may be useful biomarkers for predicting hematological toxicity or nephrotoxicity after neoadjuvant chemoradiotherapy for ESCC.

There were 415,000 deaths from esophageal cancer in 2016 (1), making it the sixth-leading cause of cancer-related deaths worldwide. Surgical resection is a reliable treatment for esophageal cancer, but a large number of patients develop locoregional recurrence or distant metastasis in the early period after surgery, and the prognosis of such patients is poor (2). Therefore, neoadjuvant chemotherapy or chemoradiotherapy has been administered before surgery in certain studies in an attempt to improve tumor resectability and survival in patients with locally advanced esophageal cancer (3-6), and it was reported that neoadjuvant chemoradiotherapy accompanied by surgery improved the overall survival of patients with potentially curable esophageal cancer (5-7). However, one of the problems with neoadjuvant chemoradiotherapy, especially chemotherapy, is its side-effects. For example, approximately one-third of patients who receive cisplatin subsequently suffer renal 
Table I. Characteristics of the patients enrolled in this study. Regarding the grading of hematological toxicity based on the Common Terminology Criteria for Adverse Events (CTCAE) (13). grade 1 and 2 were considered to indicate the absence of side-effects, and grade 3 and 4 were considered to indicate the presence of side-effects. In the grading of nephrotoxicity based on the CTCAE, grade 0 was considered to indicate the absence of side-effects, and grade 1 and 2 were considered to indicate the presence of side-effects.

\begin{tabular}{|c|c|c|c|c|c|c|}
\hline & \multicolumn{3}{|c|}{ Hematological toxicity (CTCAE) ${ }^{\mathrm{a}}$} & \multicolumn{3}{|c|}{ Nephrotoxicity $(\mathrm{CTCAE})^{\mathrm{b}}$} \\
\hline & Grade $1 \& 2(n=8)$ & Grade $3 \& 4(n=18)$ & $p$-Value* & Grade $0(n=18)$ & Grade $1 \& 2(n=8)$ & $p$-Value* \\
\hline \multicolumn{7}{|l|}{ Age } \\
\hline$<65$ Years & 5 & 12 & $>0.99$ & 13 & 4 & 0.382 \\
\hline$\geq 65$ Years & 3 & 6 & & 5 & 4 & \\
\hline \multicolumn{7}{|l|}{ Gender } \\
\hline Male & 7 & 16 & $>0.99$ & 16 & 7 & $>0.99$ \\
\hline Female & 1 & 2 & & 2 & 1 & \\
\hline \multicolumn{7}{|c|}{ Tumor location } \\
\hline $\mathrm{Lt}$ & 3 & 8 & $>0.99$ & 7 & 4 & $>0.99$ \\
\hline Mt & 5 & 9 & & 10 & 4 & \\
\hline Ut & 0 & 1 & & 1 & 0 & \\
\hline \multicolumn{7}{|c|}{ Clinical stage } \\
\hline IIA & 0 & 1 & $>0.99$ & 0 & 1 & 0.442 \\
\hline IIB & 3 & 7 & & 7 & 3 & \\
\hline III & 5 & 10 & & 11 & 4 & \\
\hline \multicolumn{7}{|c|}{ Performance status } \\
\hline 0 & 5 & 11 & $>0.99$ & 13 & 3 & 0.189 \\
\hline 1 & 3 & 7 & & 5 & 5 & \\
\hline
\end{tabular}

Lt: Lower thoracic esophagus; Mt: mid thoracic esophagus; Ut: upper thoracic esophagus. ${ }^{a}$ White blood cell count/neutrophil count decreased;

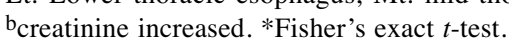

dysfunction, which is a serious side-effect $(8,9)$. Such sideeffects reduce the quality of life of patients and can delay surgery. Therefore, it is expected that reliable methods for predicting the side-effects of chemoradiotherapy would make such treatment safer and promote personalized medicine.

In this study, we performed gas chromatography/mass spectrometry (GC/MS)- and liquid chromatography/mass spectrometry (LC/MS)-based untargeted metabolomic analysis of serum samples from patients with esophageal cancer who received neoadjuvant chemoradiotherapy before undergoing surgical resection. We then tried to identify biomarker candidates that might be used to predict the sideeffects of chemoradiotherapy for esophageal cancer. Next, a targeted metabolome analysis was conducted to quantify the serum levels of the candidate predictive biomarkers identified during the untargeted metabolomic analysis. Metabolomics targets low-molecular-weight metabolites and is considered to be a useful approach because metabolites represent the endpoint of the metabolic cascade, and metabolite profiles can be directly linked to molecular phenotypes. Therefore, the levels of metabolites or metabolite profiles directly reflect the underlying biochemical activity and state of cells/tissues. As a result, metabolite levels can be analyzed to discover candidate biomarkers that might aid disease diagnosis or prediction, as indicated in a review article by Spratlin et al. (10), and we employed this approach in the present study in order to identify predictors of the side-effects of neoadjuvant chemoradiotherapy.

\section{Patients and Methods}

Patients and serum samples. Serum samples from the 26 stage IIIII (excluding T4) patients with esophageal squamous cell carcinoma (ESCC) who were enrolled in a phase II clinical trial of neoadjuvant chemoradiotherapy conducted at the National Cancer Center Hospital and National Cancer Center Hospital East between 2010 and 2011 were analyzed (11). ESCC was pathologically diagnosed via pretreatment endoscopic biopsy examinations and clinically staged according to the Union for International Cancer Control TNM cancer staging system (the 6th and 7th editions) (12). The inclusion criteria were also as follows: Having a tumor that was restricted to the thoracic esophagus; having an Eastern Cooperative Oncology Group performance status score of 0-1; being aged 20-75 years; possessing evaluable lesions; having no history of pretreatment procedures, except for endoscopic resection, for ESCC; having no history of radiotherapy or chemotherapy for other malignant tumors; not having bilateral recurrent nerve paralysis; having sufficient organ function; and it being judged that curative ESCC surgery via open thoracotomy was possible. The neoadjuvant chemoradiotherapy consisted of two courses of a protracted 5-fluorouracil (5-FU) infusion $\left(1,000 \mathrm{mg} / \mathrm{m}^{2} /\right.$ day, days 1-4) and a 2 -h cisplatin infusion $\left(75 \mathrm{mg} / \mathrm{m}^{2}\right.$, day 1$)$, with a 4 -week interval between the courses, and concurrent radiotherapy (1.8 Gy/day, total radiation dose $=41.4 \mathrm{~Gy}$ ). Transthoracic 

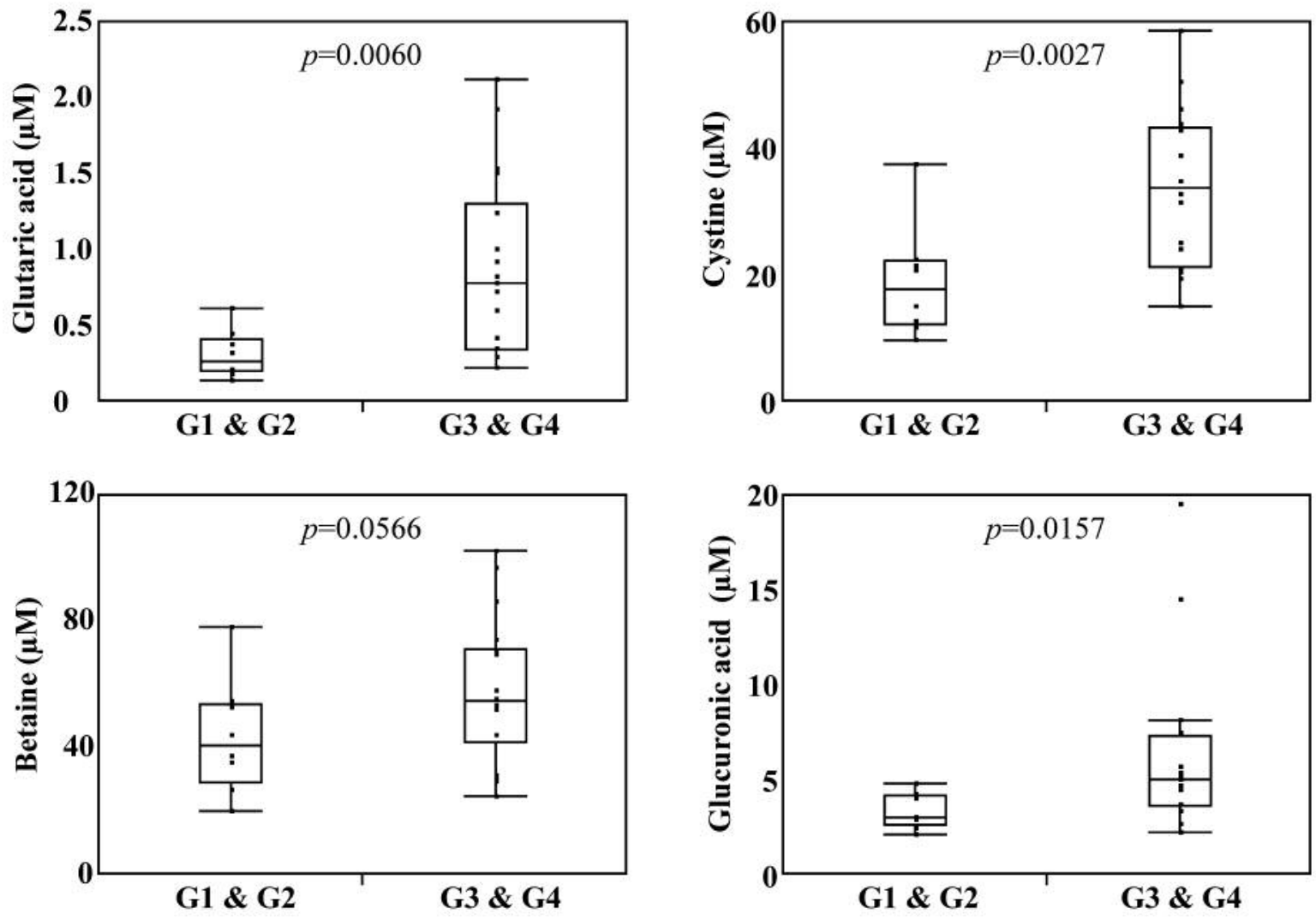

Figure 1. Box plot of the levels of the targeted metabolites in patients with and without hematological toxicity (white blood cell count/neutrophil count decreased). The boxes denote interquartile ranges. The mean is represented by the horizontal line inside the box. The whiskers (the lines extending from each box) describe the spread of the data between the 10th and 90th percentiles. The dots represent data points beyond the 10th and 90th percentiles.

esophagectomy combined with extensive lymphadenectomy $(>\mathrm{D} 2)$ was performed at 6 to 8 weeks after the completion of the chemoradiotherapy. The side-effects of the neoadjuvant chemotherapy were evaluated by examining the patients for hematological toxicity [by assessing white blood cell (WBC) and neutrophil counts] and nephrotoxicity (by measuring serum level of creatinine), and these adverse events were graded according to the Common Terminology Criteria for Adverse Events (CTCAE), which was released by National Cancer Institute (13). The serum samples were collected immediately before the initiation of neoadjuvant therapy and were frozen and stored at $-80^{\circ} \mathrm{C}$ until the analysis. This study was approved by the Ethics Committee of the National Cancer Center (permission number: 2015-041) and Kobe University Graduate School of Medicine (permission number: 1821). Written informed consent was obtained from all patients.

GC/MS and LC/MS procedures. The extraction and derivatization procedures for the GC/MS and LC/MS analyses, and the subsequent GC/MS and LC/MS analyses were performed according to the methods described in our previous report (14). In the GC/MS-based quantitative analysis of the targeted metabolites, which included betaine, glutaric acid, xylose, cystine, pyruvic acid, and glucuronic acid (Wako Pure Chemical, Osaka, Japan), the peak area of each metabolite was corrected using data for the corresponding stable isotope, which were $\left[\mathrm{D}_{11}\right]$-labeled betaine, $\left[2,2,4,4-\mathrm{D}_{4}\right]$-labeled glutaric acid, $\left[\mathrm{U}^{1}{ }^{13} \mathrm{C}_{5}\right]$-labeled xylose, [3,3,3',3'- $\left.\mathrm{D}_{4}\right]$-labeled cystine, $\left[{ }^{13} \mathrm{C}_{3}\right]$-labeled sodium pyruvate, and $\left[\mathrm{U}-{ }^{13} \mathrm{C}_{6}\right]$-labeled glucuronic acid (Cambridge Isotope Laboratories, Andover, MA, USA), respectively. Quantitation was conducted based on multipoint calibration curves.

Statistical analysis. The statistical significance of differences in the characteristics of the patients enrolled in this study was evaluated using Fisher's exact $t$-test. In the comprehensive and semiquantitative metabolome analysis, the statistical significance of differences was evaluated using the Mann-Whitney $U$-test. In the targeted and quantitative metabolomic analysis, the statistical significance of differences was evaluated using Student's $t$-test, Welch's t-test, or Mann-Whitney $U$-test accompanied by the Shapiro-Wilk test and F-test.

\section{Results}

Patients and treatment outcomes. All 26 patients were able to complete the same neoadjuvant chemoradiotherapy regimen (cisplatin plus 5-FU and concurrent radiotherapy) and underwent radical esophagectomy combined with D2 lymphadenectomy. The clinical characteristics of the patients are shown in Table I. Hematological toxicity and nephrotoxicity 

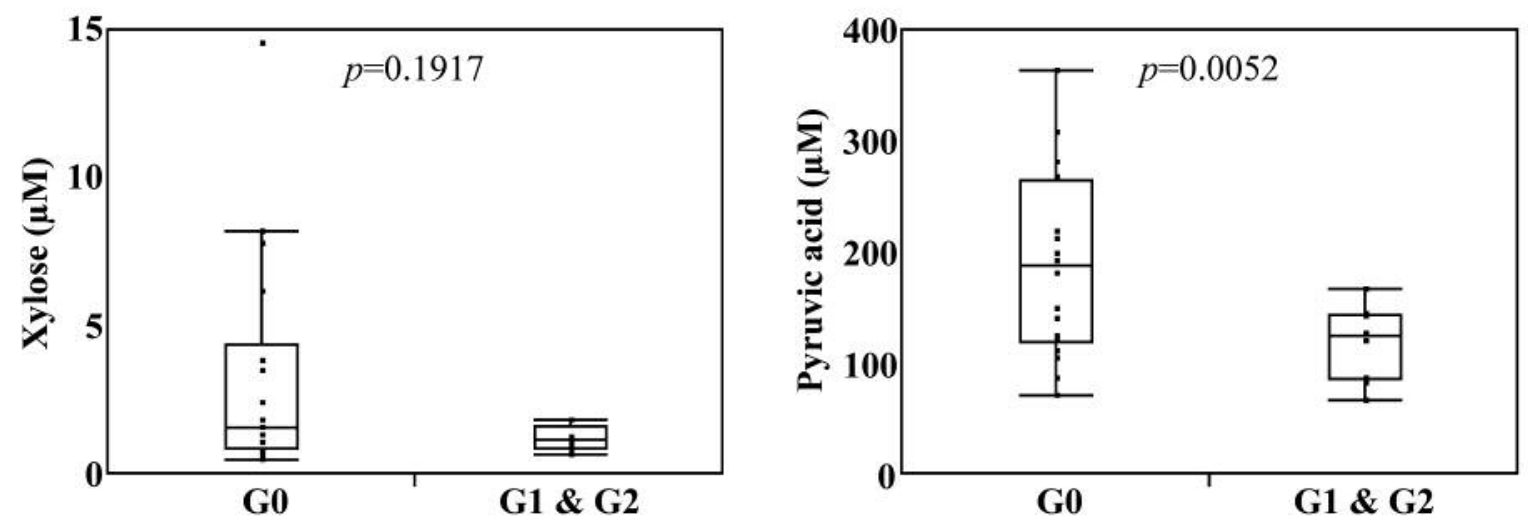

Figure 2. Box plot of the levels of the targeted metabolites in the patients with and without nephrotoxicity (creatinine increased). The boxes denote interquartile ranges. The mean is represented by the horizontal line inside the box. The whiskers (the lines extending from each box) describe the spread of the data between the 10th and 90th percentiles. The dots represent data points beyond the 10th and 90th percentiles.

were classified based on the CTCAE. For hematological toxicity, grade 1 and 2 were considered to indicate that such side-effects were absent $(\mathrm{N}=8)$, whereas grade 3 and 4 were considered to indicate that such side-effects were present $(\mathrm{N}=18)$. For nephrotoxicity, grade 0 was considered to indicate that such side-effects were absent $(\mathrm{N}=18)$, and grade 1 and 2 were considered to indicate that such side-effects were present $(\mathrm{N}=8)$. For both hematological toxicity and nephrotoxicity, there were no significant differences in age, gender, tumor location, clinical stage, or performance status between patients with and without side-effects.

Serum metabolites associated with the side-effects of neoadjuvant chemoradiotherapy for ESCC. In the LC/MSand GC/MS-based comprehensive and semi-quantitative analysis, a total of 322 metabolites were detected in the patients' sera (including some metabolites that were detected using both LC/MS and GC/MS). Firstly, the serum levels of metabolites were compared between the groups with and without side-effects for both hematological toxicity and nephrotoxicity using the Mann-Whitney $U$-test. Twenty-five metabolites exhibited significant differences in their levels between the patients with and without hematological toxicity $(p<0.05)$, whereas 35 metabolites displayed significant differences in their levels between the patients with and without nephrotoxicity $(p<0.05)$.

Quantitative measurements of serum levels of predictive biomarker candidates. In order to obtain more precise quantitative data, we performed targeted metabolomic analysis in which we used corresponding stable isotopes because the use of stable isotopes to normalize serum metabolite concentration data makes it possible to quantify the levels of targeted metabolites more accurately (15). In this study, we obtained stable isotopes corresponding to glutaric acid, cystine, betaine, and glucuronic acid, whose levels were found to differ significantly $(p<0.05)$ between the patients with and without hematological toxicity in the semi-quantitative analysis, and xylose and pyruvic acid, whose levels were found to differ significantly $(p<0.05)$ between the patients with and without nephrotoxicity in the semi-quantitative analysis. In the targeted analysis of hematological toxicity, the serum levels of glutaric acid $(p=0.0060)$, cystine $(p=0.0027)$, and glucuronic acid ( $p=0.0157)$ were significantly higher in the group with such side-effects than in those without such side-effects (Figure 1). Furthermore, the serum level of betaine ( $p=0.0566)$ tended to be higher in patients with hematological toxicity (Figure 1). Regarding nephrotoxicity, patients with such side-effects exhibited lower serum levels of pyruvic acid $(p=0.0052)$ than those without such side-effects (Figure 2). In addition, the serum level of xylose $(p=0.1917)$ tended to be lower in patients with nephrotoxicity (Figure 2).

Subclass analysis of lipid species that might be used to predict the side-effects of neoadjuvant chemoradiotherapy for ESCC. Based on the results of the LC/MS-based comprehensive and semi-quantitative analysis, a subclass analysis of lipid species was performed to identify lipid species that might be used to predict the side-effects of neoadjuvant chemoradiotherapy for ESCC using a volcano plot (Figure 3 ). The volcano plot of the detected lipid species showed a tendency towards high levels of phosphatidylcholines (PC) and phosphatidylethanolamines (PE) in patients with hematological toxicity. For nephrotoxicity, the volcano plot exhibited a tendency towards low levels of lysophosphatidylcholines (LPC) and lyso-phosphatidylethanolamines (LPE) in patients with side-effects. 
A

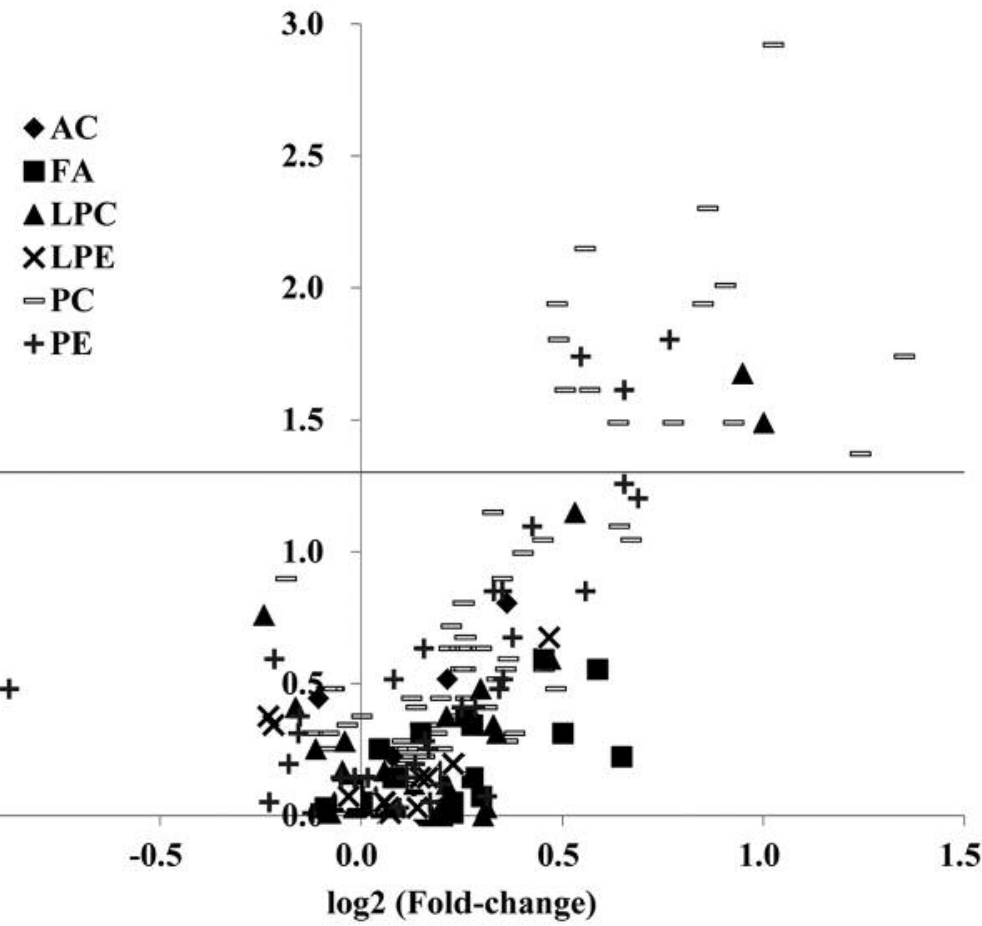

B

$\log 2$ (Fold-change)

\section{5}

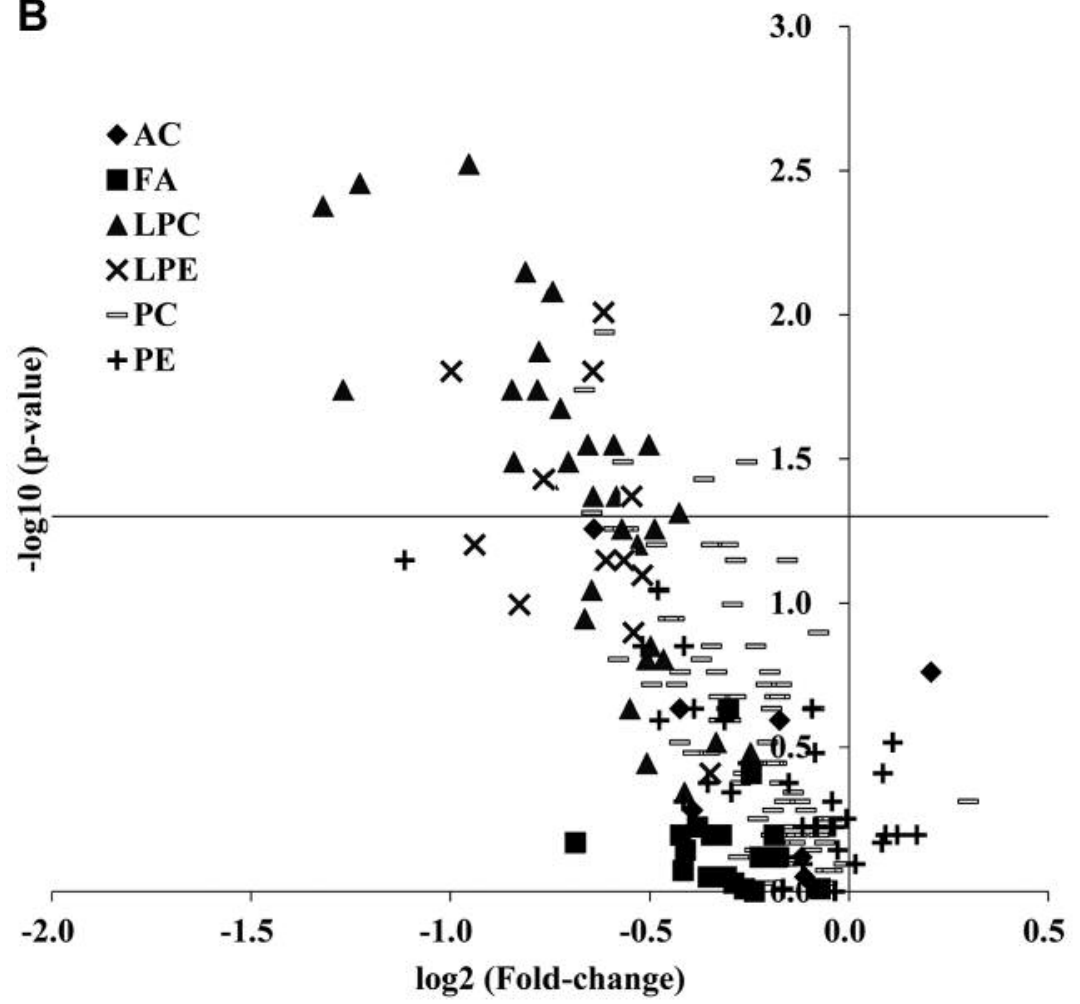

Figure 3. Volcano plot of the associations between the levels of lipid species and hematological toxicity (white blood cell count/neutrophil count decreased) (A) or nephrotoxicity (creatinine increased) (B). X axis: Fold-change values (on a log2 scale) obtained during comparisons of lipid species levels between the grade $3 / 4$ and grade 1/2 groups for hematological toxicity and between the grade 1/2 and grade 0 groups for nephrotoxicity; $Y$ axis: - $\log 10$ (p-value). p-Values were calculated using the Mann-Whitney U-test. The horizontal lines represent p-values of 0.05. AC: Acylcarnitines, FA: fatty acids, LPC: lysophosphatidylcholines, LPE: lysophosphatidylethanolamines, PC: phosphatidylcholines, PE: phosphatidylethanolamines. 


\section{Discussion}

Side-effects from neoadjuvant chemoradiotherapy, especially chemotherapy, are an unavoidable problem and reduce patient QOL. For example, cytopenia, kidney disorders, and bone-marrow suppression are known side-effects of cisplatin therapy. The side-effects of 5-FU therapy include diarrhea, cytopenia, and bone-marrow suppression. Therefore, reliable methods for predicting the side-effects of chemoradiotherapy are needed to make such treatment as safe as possible and promote personalized medicine. In the present study, we tried to identify biomarker candidates that might be used to predict the side-effects of chemoradiotherapy involving cisplatin and 5-FU for ESCC.

Chemoradiotherapy targets rapidly dividing cells, therefore it attacks normal cells as well as cancer cells, resulting in a variety of side-effects. 5-FU inhibits the activity of thymidylate synthase, resulting in inhibition of DNA synthesis. Cisplatin binds to cellular DNA and causes platinum-DNA adduct formation, leading to prevention of DNA replication and transcription. Radiation causes direct DNA damage, which inhibits DNA replication and transcription. Normally, when DNA damage occurs, the affected cells initiate a DNA repair reaction, which leads to genomic homeostasis. If the DNA repair reaction could be induced more efficiently in normal cells, fewer normal cells would undergo cell death, resulting in the suppression of hematological toxicity. In our study, higher levels of PC and PE were detected in serum from patients that suffered hematological toxicity (Figure 3). In addition, the serum levels of glutaric acid, cystine, and glucuronic acid were significantly higher in patients with hematological toxicity (Figure 1). It is known that an elevated level of glutaric acid can have toxic effects, and glutaric acid can induce brain damage via energy depletion (16) and oxidative stress (17). These findings are related to brain toxicity, but higher levels of glutaric acid in the body may easily induce hematological toxicity. As far as we are aware, there are no reports about the relationships between the levels of PC, $\mathrm{PE}$, cystine, or glucuronic acid and hematological toxicity, and further investigations of these associations are needed.

Nephrotoxicity is a serious problem in patients treated with cisplatin. Cisplatin is absorbed into renal tubular cells, and exposing tubular cells to cisplatin triggers signaling pathways involving reactive oxygen species or p53 and mitogen-activated protein kinase pathways, leading to promotion of cell death. Cisplatin also induces inflammatory responses and renal vascular injury, and these events can ultimately lead to acute renal failure $(18,19)$. If renal cells were more resistant to oxidative stress, inflammation, etc., the degree of kidney damage due to cisplatin would be reduced. In our study, the patients with higher levels of LPC and LPE experienced fewer renal side-effects (Figure 3). In addition, the patients with side-effects had lower serum levels of pyruvic acid than those without side-effects (Figure 2). Pyruvic acid, which is a key metabolite for energy metabolism, might reduce in vitro and in vivo nephrotoxicity caused by $p$-aminophenol (20) or glycerol (21), as it contributes to the maintenance of glutathione status and helps to prevent lipid peroxidation. Therefore, patients with higher serum levels of pyruvic acid might experience lower levels of oxidative stress, and hence, be more resistant to nephrotoxicity, although the associations between LPC or LPE and nephrotoxicity seen in the current study cannot be explained at present.

Regarding factors that can be used to predict the sideeffects of anticancer drugs, gene polymorphisms affecting drug-metabolizing enzymes are known to be useful for this purpose, and it has recently been reported that the detection of rare dihydropyrimidine dehydrogenase gene variants might make it possible to predict severe side-effects of 5FU-based chemotherapy in the Japanese population (22). However, evaluations of polymorphisms in genes for drugmetabolizing enzymes are usually performed using tissues/cells, rather than blood. Regarding serum metabolites, animal experiments have indicated that the serum levels of branched-chain amino acids might be useful for predicting nephrotoxicity (23). In our human study, the serum levels of branched-chain amino acids did not differ significantly between the patients with and without side-effects, but the serum levels of some of the metabolites identified in the current study might represent the degree of resistance a patient possesses to hematological toxicity or nephrotoxicity. We found that the serum levels of some metabolites differed significantly between the patients with and without side-effects, so these metabolites might be useful biomarkers for predicting hematological toxicity or nephrotoxicity. However, the sets of biomarker candidates identified for hematological toxicity and nephrotoxicity were not identical, suggesting that these candidates might reflect some specific characteristics of each type of toxicity. The limitations of our study include the small sample size, and a further largescale prospective study is required to validate our findings and evaluate their clinical applicability. Thus, our study must be viewed as the first step in the identification of blood metabolite biomarkers that might be used to predict side-effects of neoadjuvant chemoradiotherapy for ESCC.

\section{Acknowledgements}

This study was supported in part by a Grant-in-Aid for Scientific Research (B) from the Japan Society for the Promotion of Science (16H05227) (M.Y.) and the AMED-CREST by the Japan Agency for Medical Research and Development (18gm0710013h0005) (M.Y.). 


\section{References}

1 Global Burden of Disease Cancer Collaboration, Fitzmaurice C, Akinyemiju TF, Al Lami FH, Alam T, Alizadeh-Navaei R, Allen C, Alsharif U, Alvis-Guzman N, Amini E, Anderson BO, Aremu O, Artaman A, Asgedom SW, Assadi R, Atey TM, Avila-Burgos L, Awasthi A, Ba Saleem HO, Barac A, Bennett JR, Bensenor IM, Bhakta N, Brenner H, Cahuana-Hurtado L, Castañeda-Orjuela CA, Catalá-López F, Choi JJ, Christopher DJ, Chung SC, Curado MP, Dandona L, Dandona R, das Neves J, Dey S, Dharmaratne SD, Doku DT, Driscoll TR, Dubey M, Ebrahimi H, Edessa D, ElKhatib Z, Endries AY, Fischer F, Force LM, Foreman KJ, Gebrehiwot SW, Gopalani SV, Grosso G, Gupta R, Gyawali B, Hamadeh RR, Hamidi S, Harvey J, Hassen HY, Hay RJ, Hay SI, Heibati B, Hiluf MK, Horita N, Hosgood HD, Ilesanmi OS, Innos K, Islami F, Jakovljevic MB, Johnson SC, Jonas JB, Kasaeian A, Kassa TD, Khader YS, Khan EA, Khan G, Khang YH, Khosravi MH, Khubchandani J, Kopec JA, Kumar GA, Kutz M, Lad DP, Lafranconi A, Lan Q, Legesse Y, Leigh J, Linn S, Lunevicius R, Majeed A, Malekzadeh R, Malta DC, Mantovani LG, McMahon BJ, Meier T, Melaku YA, Melku M, Memiah P, Mendoza W, Meretoja TJ, Mezgebe HB, Miller TR, Mohammed S, Mokdad AH, Moosazadeh M, Moraga P, Mousavi SM, Nangia V, Nguyen CT, Nong VM, Ogbo FA, Olagunju AT, Pa M, Park EK, Patel T, Pereira DM, Pishgar F, Postma MJ, Pourmalek F, Qorbani M, Rafay A, Rawaf S, Rawaf DL, Roshandel G, Safiri S, Salimzadeh H, Sanabria JR, Santric Milicevic MM, Sartorius B, Satpathy M, Sepanlou SG, Shackelford KA, Shaikh MA, Sharif-Alhoseini M, She J, Shin MJ, Shiue I, Shrime MG, Sinke AH, Sisay M, Sligar A, Sufiyan MB, Sykes BL, Tabarés-Seisdedos R, Tessema GA, Topor-Madry R, Tran TT, Tran BX , Ukwaja KN, Vlassov VV, Vollset SE, Weiderpass E, Williams HC, Yimer NB, Yonemoto N, Younis MZ, Murray CJL and Naghavi M: Global, regional, and national cancer incidence, mortality, years of life lost, years lived with disability, and disability-adjusted life-years for 29 cancer groups, 1990 to 2016: A systematic analysis for the Global Burden of Disease Study. JAMA Oncol 4: 1553-1568, 2018.

2 Parry K, Visser E, van Rossum PSN, Mohammad NH, Ruurda JP and van Hillegersberg R: Prognosis and treatment after diagnosis of recurrent esophageal carcinoma following esophagectomy with curative intent. Ann Surg Oncol 22: 1292-1300, 2015.

3 Kelsen DP, Winter KA, Gunderson LL, Mortimer J, Estes NC, Haller DG, Ajani JA, Kocha W, Minsky BD, Roth JA and Willett CG; Radiation Therapy Oncology Group; USA Intergroup: A random assignment trial comparison of chemotherapy followed by surgery compared with surgery alone for esophageal cancer. J Clin Oncol 25: 3719-3725, 2007.

4 Allum WH, Stenning SP, Bancewicz J, Clark PI and Langley RE: Long-term results of a randomized trial of surgery with or without preoperative chemotherapy in esophageal cancer. J Clin Oncol 27: 5062-5067, 2009.

5 van Hagen P, Hulshof MC, van Lanschot JJ, Steyerberg EW, van Berge Henegouwen MI, Wijnhoven BP, Richel DJ, Nieuwenhuijzen GA, Hospers GA, Bonenkamp JJ, Cuesta MA, Blaisse RJ, Busch OR, ten Kate FJ, Creemers GJ, Punt CJ, Plukker JT, Verheul HM, Spillenaar Bilgen EJ, van Dekken H, van der Sangen MJ, Rozema T, Biermann K, Beukema JC, Piet AH, van Rij CM, Reinders JG, Tilanus HW and van der Gaast A; CROSS Group: Preoperative chemoradiotherapy for esophageal or junctional cancer. N Engl J Med 366: 2074-2084, 2012.
6 Shapiro J, van Lanschot JJB, Hulshof MCCM, van Hagen P, van Berge Henegouwen MI, Wijnhoven BPL, van Laarhoven HWM, Nieuwenhuijzen GAP, Hospers GAP, Bonenkamp JJ, Cuesta MA, Blaisse RJB, Busch ORC, Ten Kate FJW, Creemers GM, Punt CJA, Plukker JTM, Verheul HMW, Bilgen EJS, van Dekken H, van der Sangen MJC, Rozema T, Biermann K, Beukema JC, Piet AHM, van Rij CM, Reinders JG, Tilanus HW, Steyerberg EW and van der Gaast A; CROSS study group: Neoadjuvant chemoradiotherapy plus surgery versus surgery alone for oesophageal or junctional cancer (CROSS): Longterm results of a randomised controlled trial. Lancet Oncol 16: 1090-1098, 2015.

7 Sjoquist KM, Burmeister BH, Smithers BM, Zalcberg JR, Simes RJ, Barbour A and Gebski V; Australasian Gastro-Intestinal Trials Group: Survival after neoadjuvant chemotherapy or chemoradiotherapy for resectable oesophageal carcinoma: An updated meta-analysis. Lancet Oncol 12: 681-692, 2011.

8 Arany I and Safirstein RL: Cisplatin nephrotoxicity. Semin Nephrol 23: 460-464, 2003.

9 Bajorin DF, Bosl GJ, Alcock NW, Niedzwiecki D, Gallina E and Shurgot B: Pharmacokinetics of cis-diamminedichloroplatinum(II) after administration in hypertonic saline. Cancer Res 46: 5969-5972, 1986.

10 Spratlin JL, Serkova NJ and Eckhardt SG: Clinical applications of metabolomics in oncology: A review. Clin Cancer Res 15: 431-440, 2009.

11 Hashimoto J, Kato K, Ito Y, Kojima T, Akimoto T, Daiko H, Hamamoto Y, Matsushita H, Katano S, Hara H, Tanaka Y, Saito Y, Nagashima K and Igaki H: Phase II feasibility study of preoperative concurrent chemoradiotherapy with cisplatin plus 5-fluorouracil and elective lymph node irradiation for clinical stage II/III esophageal squamous cell carcinoma. Int J Clin Oncol https://doi.org/10.1007/s10147-018-1336-x, 2018.

12 Sobin LH and Wittekind C: TNM Classification of Malignant Tumours, Seventh Edition. Sobin LH, Gospodarowicz MK and Wittekind C (Eds.). John Wiley \& Sons, Inc., pp. 1-336, 2011.

13 Common Terminology Criteria for Adverse Events (CTCAE) Version 4.0

U.S. Department of Health and Human Services National Institutes of Health National Cancer Institute, available at: https://evs.nci.nih.gov/ftp1/CTCAE/CTCAE_4.03/Archive/CTC AE_4.0_2009-05-29_QuickReference_8.5x11.pdf (last accessed 29/11/2018).

14 Fujigaki S, Nishiumi S, Kobayashi T, Suzuki M., Iemoto T, Kojima T, Ito Y, Daiko H, Kato K, Shouji H, Honda K, Azuma $\mathrm{T}$ and Yoshida M: Identification of serum biomarkers of chemoradiosensitivity in esophageal cancer via the targeted metabolomics approach. Biomark Med 12: 827-840, 2018.

15 Bueschl C, Krska R, Kluger B and Schuhmacher R: Isotopic labeling-assisted metabolomics using LC-MS. Anal Bioanal Chem 405: 27-33, 2013.

16 Ferreira Gda C, Viegas CM, Schuck PF, Tonin A, Ribeiro CA, Coelho Dde M, Dalla-Costa T, Latini A, Wyse AT, Wannmacher CM, Vargas CR and Wajner M: Glutaric acid administration impairs energy metabolism in midbrain and skeletal muscle of young rats. Neurochem Res 30: 1123-1131, 2005.

17 de Oliveira Marques F, Hagen ME, Pederzolli CD, Sgaravatti AM, Durigon K, Testa CG, Wannmacher CM, de Souza Wyse AT, Wajner M and Dutra-Filho CS: Glutaric acid induces oxidative stress in brain of young rats. Brain Res 964: 153-158, 2003. 
18 Ozkok A and Edelstein CL: Pathophysiology of cisplatininduced acute kidney injury. BioMed Res Int 2014: 967826, 2014.

19 Pabla N and Dong Z: Cisplatin nephrotoxicity: mechanisms and renoprotective strategies. Kidney International 73: 994-1007, 2008.

20 Harmon RC, Kiningham KK and Valentovic MA: Pyruvate reduces 4-aminophenol in vitro toxicity. Toxicol Appl Pharmacol 213: 179-86, 2006.

21 Salahudeen AK, Clark EC and Nath KA: Hydrogen peroxideinduced renal injury. A protective role for pyruvate in vitro and in vivo. Clin Invest 88: 1886-1893, 1991.

22 Hishinuma E, Narita Y, Saito S, Maekawa M, Akai F, Nakanishi Y, Yasuda J, Nagasaki M, Yamamoto M, Yamaguchi H, Mano N, Hirasawa N and Hiratsuka M: Functional characterization of 21 allelic variants of dihydropyrimidine dehydrogenase identified in 1070 Japanese individuals. Drug Metab Dispos 46: 10831090, 2018.

23 Zhang P, Li W, Chen J, Li R, Zhang Z, Huang Y and Xu F: Branched-chain amino acids as predictors for individual differences of cisplatin nephrotoxicity in rats: A Pharmacometabonomics Study. J Proteome Res 16: 1753-1762, 2017.

Received November 15, 2018

Revised November 29, 2018

Accepted November 30, 2018 